\title{
Mortality of Patients with Hematological Malignancy after Admission to the Intensive Care Unit
}

\author{
Sophia Horster ${ }^{a} \quad$ H. Joachim Stemmler ${ }^{b}$ Philipp C. Mandel ${ }^{a} \quad$ Alexander Mück $^{a}$ \\ Johanna Tischer $^{\mathrm{b}} \quad$ Andreas Hausmann $^{\mathrm{b}} \quad$ Klaus G. Parhofer ${ }^{\mathrm{a}} \quad$ Sandra Geiger $^{\mathrm{b}}$
}

${ }^{a}$ Medical Department II,

${ }^{b}$ Medical Department III, Intensive Care Unit, Ludwig Maximilian University of Munich, Campus Großhadern, Munich, Germany

Keywords

Intensive care unit · Cancer · Mortality · Prognosis

\section{Summary}

Background: The admission of patients with malignancies to an intensive care unit (ICU) still remains a matter of substantial controversy. The identification of factors that potentially influence the patient outcome can help ICU professionals make appropriate decisions. Patients and Methods: 90 adult patients with hematological malignancy (leukemia 47.8\%, high-grade lymphoma $50 \%$ ) admitted to the ICU were analyzed retrospectively in this single-center study considering numerous variables with regard to their influence on ICU and day-100 mortality. Results: The median simplified acute physiology score (SAPS) II at ICU admission was 55 (ICU survivors 47 vs. 60.5 for non-survivors). The overall ICU mortality rate was $45.6 \%$. With multivariate regression analysis, patients admitted with sepsis and acute respiratory failure had a significantly increased ICU mortality (sepsis odds ratio (OR) 9.12, 95\% confidence interval (CI) 1.199.7, $\mathrm{p}=0.04$; respiratory failure OR $13.72,95 \% \mathrm{Cl} 1.39$ $136.15, p=0.025)$. Additional factors associated with an increased mortality were: high doses of catecholamines (ICU: OR 7.37, p = 0.005; day 100: hazard ratio (HR) 2.96, $p<0.0001$ ), renal replacement therapy (day 100: HR 1.93, $\mathrm{p}=0.026$ ), and high SAPS II (ICU: HR 1.05, $p=0.038$; day 100: HR 1.2, $p=0.027)$. Conclusion: The decision for or against ICU admission of patients with hematological diseases should become increasingly independent of the underlying malignant disease.
Schlüsselwörter

Intensivstation · Krebs · Mortalität · Prognose

\section{Zusammenfassung}

Hintergrund: Die Verlegung von hämatologisch-onkologischen Patienten auf die Intensivstation (ICU) wird kontrovers diskutiert. Die Identifizierung von prognostisch bestimmenden Faktoren könnte Intensivmedizinern und Onkologen bei einer adäquaten Entscheidungsfindung helfen. Patienten und Methoden: 90 erwachsene, intensivpflichtige Patienten mit hämatologischer Grunderkrankung (Leukämie 47,8\%, hochmaligne Lymphome 50\%) wurden retrospektiv in einer monozentrischen Studie hinsichtlich verschiedener Variablen und deren Bedeutung auf die ICU- und Tag-100-Mortalität analysiert. Ergebnisse: Der mediane Simplified Acute Physiology Score (SAPS) II zum Zeitpunkt der ICU-Verlegung betrug 55 (ICU-Überlebende 47 vs. 60,5 für ICU-Nichtüberlebende), die Mortalitätsrate $45,6 \%$. Mit einer multivariaten Regressionsanalyse zeigte sich eine signifikant erhöhte ICU-Mortalitätsrate von Patienten mit der Zuweisungsdiagnose "Sepsis" oder "akute respiratorische Insuffizienz" (Sepsis Odds Ratio (OR) 9,12, 95\% Konfidenzintervall (Cl) 1,1-99,7, p=0,04; respiratorische Insuffizienz OR $13,72,95 \% \mathrm{Cl} 1,39-136,15, p=0,025)$. Weitere, mit einer erhöhten Mortalität assoziierte Faktoren waren: hohe Katecholamindosen (ICU: OR 7,37, p = 0,005; Tag 100: HR 2,96, $p<0,0001$ ), Nierenersatztherapie (Tag 100: HR 1,93, $p=0,026$ ) und hoher SAPS II (ICU: HR 1,05, $p=0,038$; Tag 100: HR 1,2, $p=0,027)$. Schlussfolgerung: Die Entscheidung, ob hämatologisch-onkologische Patienten auf die Intensivstation verlegt werden, sollte weniger von der Grunderkrankung selbst als vielmehr von Parametern abhängen, die die akute Intensivpflichtigkeit bedingen.

\section{KARGER}

Fax +497614520714

Information@Karger.de

www.karger.com (c) 2012 S. Karger GmbH, Freiburs

0378-584X/12/3510-0556\$38.00/0

Accessible online at:

www.karger.com/onk
Prof. Dr. Hans Joachim Stemmle

Medical Dept. III - Intensive Care Unit

Ludwig Maximilian University Munich, Campus Großhadern

Marchioninistr. 15, 81377 Munich, Germany

Tel. +49 89 7095-6017, Fax -8897

Joachim.stemmler@med.uni-muenchen.de 


\section{Introduction}

Admission of patients with a hematological malignancy (HM) on an intensive care unit (ICU) is subject to controversial discussion. Life expectancy of these patients is often reduced due to the underlying malignant disease. Based on the underlying disease and the subsequent chemotherapy, they typically develop infectious complications after admission to the ICU. In the literature, respiratory failure (41-45\%) and sepsis (24$33 \%$ ) were the main reasons for an ICU admission and the ICU mortality ranked between 30 and $69 \%$ in these patients [1-3]. Nevertheless, an ICU stay may bridge a transitory complication and thus donate lifetime even to patients with advanced malignant diseases.

Although the overall ICU mortality in this collective is high, it does not seem to be correlated with the underlying HM. Comparable to patients without malignant disease, the outcome of these patients was adversely influenced by high points in various scores assessing organ failure, hemodynamic instability, and mechanical ventilation as parameters for the severity of the disease leading to ICU admission. Type and activity of the HM, recent chemotherapy or neutropenia did not constitute independent risk factors for ICU mortality [110]. Only bone marrow transplantation or peripheral blood stem cell transplantation (PBSCT) were associated with a worse outcome on the ICU, with a mortality as high as $2 / 3$ [8, 9]. The decision for or against an ICU admission of patients with hemato-oncological diseases becomes increasingly independent of the underlying malignant disease. Therefore, cancer patients should not be excluded from referral to the ICU in an emergency solely due to their underlying malignant disease or a single unfavorable prognostic factor [11]. More risk factors for an adverse outcome in this patient group need to be defined to direct the ICU clinicians toward an early and effective treatment. A better understanding of factors that potentially influence the patient outcome can help healthcare professionals make appropriate management decisions.

Therefore, we evaluated the characteristics and outcomes of patients to identify risk factors for adverse outcome with HMs requiring intensive care.

\section{Patients and Methods}

From November 2005 until November 2006, 90 adult patients with HM who were transferred to a 10-bed, noncardiological medical ICU at the University Hospital Munich were retrospectively evaluated. The study protocol was approved by the institutional data protection committee. Lacking any interventions, informed consent was waived.

The variables age, gender, type of HM, type of ICU admission diagnosis, length of ICU stay, simplified acute physiology score (SAPS) II on admission to the ICU, leukocyte count on admission to the ICU, maximum amount of catecholamines required, renal failure defined as need for hemodialysis or hemofiltration, and need for invasive respiratory support were analyzed retrospectively with regard to their influence on ICU and day-100 mortality [11]. The baseline characteristics are summarized in table 1.
Table 1. Baseline characteristics I $(n=90)$

\begin{tabular}{|c|c|c|}
\hline Variable & Mean (median) & Range \\
\hline Age, years & $56(58)$ & $21-85$ \\
\hline SAPS II, points & $55(55)$ & $18-118$ \\
\hline \multirow[t]{2}{*}{ Days on ICU, days } & $10(5)$ & $1-52$ \\
\hline & $\mathrm{n}$ & $\%$ \\
\hline Number of patients & 90 & 100 \\
\hline \multicolumn{3}{|l|}{ Gender } \\
\hline Male & 62 & 68.9 \\
\hline Female & 28 & 31.1 \\
\hline \multicolumn{3}{|l|}{ Underlying malignancy } \\
\hline Leukemia & 43 & 47.8 \\
\hline Lymphoma & 45 & 50.0 \\
\hline Other & 2 & 2.2 \\
\hline \multicolumn{3}{|l|}{ Reason for ICU admission } \\
\hline Sepsis & 26 & 28.9 \\
\hline Respiratory failure & 35 & 38.9 \\
\hline PI care & 17 & 18.9 \\
\hline Other & 12 & 13.3 \\
\hline \multicolumn{3}{|l|}{ Death on ICU } \\
\hline Total & 41 & 45.6 \\
\hline Sepsis & 20 & 22.2 \\
\hline Respiratory failure & 17 & 18.9 \\
\hline Other reasons & 4 & 4.4 \\
\hline \multicolumn{3}{|l|}{ Norepinephrine } \\
\hline Total & 61 & 67.8 \\
\hline$<3 \mathrm{mg} / \mathrm{h}$ & 31 & 34.4 \\
\hline$\geq 3 \mathrm{mg} / \mathrm{h}$ & 30 & 33.3 \\
\hline Vasopressin, total & 6 & 6.6 \\
\hline Mechanical ventilation, total & 52 & 57.8 \\
\hline Renal replacement,total & 19 & 21.1 \\
\hline \multicolumn{3}{|l|}{ Leukopenia } \\
\hline Total & 49 & 54.4 \\
\hline $100-3999 / \mu l$ & 33 & 36.7 \\
\hline$<100 / \mu l$ & 15 & 16.7 \\
\hline
\end{tabular}

PI care $=$ Post-interventional care (surgery, invasive procedures).

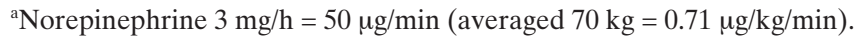

Statistical analysis was performed with STATA 11. Univariate tests were performed using the log-rank test, the Chi-squared test, and the Wilcoxon-Mann-Whitney test. Multivariate Cox regression analysis was used to analyze the influence of the variables on the day-100 mortality. Logistic regression was used to analyze the ICU mortality and to analyze the ICU stay duration with regard to mortality. A difference of $\mathrm{p}<0.05$ between the variables was considered as statistically significant.

ICU admission is considered when a cancer patient has at least 1 organ failure. The patient was evaluated by a senior intensivist and the ward oncologist and hematologist in charge of the patient. The final decision regarding ICU admission is then made by the senior intensivist. The decision was recorded in the patient chart as admission, refusal because the patient is too sick to benefit, or refusal because the patient is too well to benefit. Moreover, admission to the ICU requires patient consent and availability of lifespan-extending treatment options for the malignancy.

\section{Results}

\section{Overall Mortality Rate and Reasons for Death}

Out of 90 patients, 41 died on the ICU (overall ICU mortality rate $45.6 \%$ ). Sepsis was the main reason for death on the ICU $(\mathrm{n}=20 / 41 ; 48.8 \%)$. Within this group, the source of infection was pneumonia in 14 cases ( $70 \%$ of sepsis cases). 6 patients had a different site of infection or pneumonia and an additional focus, or the focus remained unclear (30\% of sepsis cases). 
Isolated respiratory failure without sepsis (pneumonia without sepsis) led to death in 17 patients $(41.5 \%$ of deaths). Other reasons for lethal outcome in 4 cases $(9.8 \%)$ included cardiogenic shock $(\mathrm{n}=1)$, multiorgan failure (MOV) due to cytomegalovirus (CMV)-associated rhabdomyolysis $(\mathrm{n}=1)$, MOV due to leukostasis syndrome in hyperleukocytic myeloid leukemia $(\mathrm{n}=1)$, and gastrointestinal bleeding due to a penetrating tumor $(\mathrm{n}=1)$.

The baseline characteristics are given in detail in table 1 .

Variables with Statistically Significant Influence on ICU and/or Day-100 Mortality

\section{Reason for ICU Admission}

Mechanical ventilation was necessary in 52 patients $(57.8 \%)$. Among these patients, acute respiratory failure led to ICU admission in 35 patients (38.9\%). Other reasons for mechanical ventilation were circulatory failure, airway protection in those with sopor or coma not related to sepsis, and respiratory assistance following operations and interventional procedures.
Sepsis caused ICU admission in 26 patients (28.9\%), while post-interventional observation (after surgery, bronchioalveolar lavage, cardiovascular complications) was necessary in 17 patients $(18.9 \%)$.

Other reasons were documented in 12 patients $(13.3 \%$; $\mathrm{n}=5$ sopor or coma not related to sepsis, $\mathrm{n}=3$ gastrointestinal bleeding, $\mathrm{n}=2$ cardiogenic shock, $\mathrm{n}=2$ acute renal failure, due to rhabdomyolysis in 1 case).

The overall ICU mortality rate was $45.6 \%$. With multivariate regression analysis, patients admitted with sepsis and acute respiratory failure had a significantly increased ICU mortality (sepsis odds ratio (OR) 9.12, 95\% confidence interval (CI) 1.1-99.7, $\mathrm{p}=0.04$; respiratory failure OR 13.72, 95\% CI $1.39-136.15, \mathrm{p}=0.025)$. This was consistently found for respiratory failure analyzing the mortality at day 100 (HR 2.50, 95\% CI 1.01-6.23, p = 0.048). An increased risk for ICU mortality was also found in patients admitted to the ICU for other reasons (ICU mortality: OR 22.39, 95\% CI 1.65$303.36, \mathrm{p}=0.019)$, compared to patients admitted for postinterventional observation.

Table 2. Variables analyzed for influence on ICU mortality

\begin{tabular}{|c|c|c|c|c|}
\hline \multirow[b]{2}{*}{ ICU mortality } & \multirow{2}{*}{$\begin{array}{l}\text { Univariate } \chi^{2} \text {-test } \\
\mathrm{p} \text { Value }\end{array}$} & \multicolumn{3}{|c|}{ Multivariate logistic regression } \\
\hline & & OR & CI $(95 \%)$ & $\mathrm{p}$ Value \\
\hline \multicolumn{5}{|l|}{ ICU admission diagnosis } \\
\hline Sepsis & \multirow{4}{*}{0.001} & 9.12 & $1.1-99.70$ & 0.04 \\
\hline Respiratory failure & & 13.72 & $1.39-136.15$ & 0.025 \\
\hline Others & & 22.39 & $1.65-303.36$ & 0.019 \\
\hline PI care & & Ref. & & \\
\hline \multicolumn{5}{|l|}{ Gender } \\
\hline Male & \multirow{2}{*}{0.288} & - & & \\
\hline Female & & - & & \\
\hline \multicolumn{5}{|l|}{ Age } \\
\hline$\geq 50$ years & \multirow{2}{*}{0.501} & - & & \\
\hline$<50$ years & & - & & \\
\hline \multicolumn{5}{|l|}{ Leukopenia } \\
\hline$<0.1 \mathrm{G} / 1$ & \multirow{3}{*}{0.511} & - & & \\
\hline$\geq 0.1 \mathrm{G} / 1$ & & - & & \\
\hline No leukopenia & & - & & \\
\hline \multicolumn{5}{|l|}{ Norepinephrine $^{\mathrm{a}}$} \\
\hline$\geq 3 \mathrm{mg} / \mathrm{h}$ & \multirow{2}{*}{$<0.0001$} & 7.37 & $1.83-29.76$ & 0.005 \\
\hline$<3 \mathrm{mg} / \mathrm{h}$ & & Ref. & & \\
\hline \multicolumn{5}{|l|}{ Renal replacement } \\
\hline CVVH/HD & \multirow{2}{*}{0.070} & - & & \\
\hline No renal replacement & & - & & \\
\hline \multicolumn{5}{|l|}{ SAPS II } \\
\hline$>54$ & \multirow{2}{*}{$<0.0001$} & - & & \\
\hline$\geq 54$ & & - & & \\
\hline SAPS II & - & 1.05 & $1.00-1.10$ & 0.038 \\
\hline \multicolumn{5}{|l|}{ Mechanical ventilation } \\
\hline Yes & \multirow{2}{*}{$<0.0001$} & 0.78 & $0.18-3.26$ & 0.729 \\
\hline No & & Ref. & & \\
\hline \multicolumn{5}{|l|}{ Underlying malignancy } \\
\hline Leukemia & \multirow{3}{*}{0.624} & - & & \\
\hline Lymphoma & & - & & \\
\hline Others & & - & & \\
\hline
\end{tabular}

OR = Odds ratio; Ref. = reference; CVVH = continuous veno-venous hemofiltration; $\mathrm{HD}=$ hemodialyis; PI care = post-interventional care $($ surgery, invasive procedures).

The second column shows p values of the respective univariate Chi-squared tests. A multivariate logistic regression was performed with significant variables of the univariate tests.

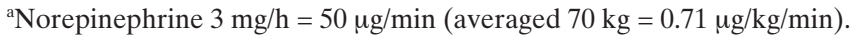


Table 3. Variables analyzed for influence on ICU mortality

\begin{tabular}{llll}
\hline ICU mortality & $\begin{array}{l}\text { Univariate Wilcoxon-Mann-Whitney test } \\
\text { p Value }\end{array}$ & $\begin{array}{l}\text { Logistic regression } \\
\text { OR }\end{array}$ & CI (95\%) \\
\hline Days on ICU & 0.027 & 1.05 & $1.01-1.09$ \\
\hline OR = Odds ratio. \\
$\begin{array}{l}\text { The second column shows the p value of the univariate Wilcoxon-Mann-Whitney test. A multivariate logistic regression was performed, } \\
\text { controlling for the underlying malignancy and the catecholamines. }\end{array}$ \\
\hline
\end{tabular}

\section{Catecholamines}

The need for catecholamines (exclusively norepinephrine) was quantified in $\mathrm{mg} / \mathrm{h}$. By multivariate regression analysis, ICU mortality and day-100 mortality were significantly increased in patients requiring high doses of norepinephrine $(\geq 3 \mathrm{mg} / \mathrm{h}=50 \mu \mathrm{g} / \mathrm{min}$, averaged $70 \mathrm{~kg}=0.71 \mu \mathrm{g} / \mathrm{kg} / \mathrm{min}$ ) compared to patients without or lower doses of catecholamines (ICU mortality: OR 7.37, 95\% CI 1.83-29.76, p = 0.005; day-100 mortality: HR 2.96, 95\% CI 1.61-5.42, $\mathrm{p}<0.0001)$. All patients requiring additional vasopressin $(n=6 / 90 ; 6.7 \%)$ died on the ICU.

\section{Renal Failure}

Patients requiring renal replacement therapy had a significantly increased day-100 mortality (HR 1.93, 95\% CI 1.08$3.46, \mathrm{p}=0.026)$.

\section{SAPS II}

ICU survivors had a median SAPS II of 47 vs. 60.5 for non-survivors. In the univariate analysis, a SAPS II above 54 points was associated with a significantly worse outcome compared to patients with a SAPS II $<54$ points (ICU mortality: $\mathrm{p}<0.0001$, day-100 mortality: $\mathrm{p}=0.0027)$. The multivariate regression analysis showed a significant influence of the SAPS II with regard to ICU mortality (OR 1.05, 95\% CI 1.00$1.10, \mathrm{p}=0.038)$ and day-100 mortality (HR 1.02, 95\% CI 1.00$1.04, \mathrm{p}=0.027$ ).

\section{Days on the ICU}

By logistic regression analysis, the length of the ICU stay was significantly associated with an increased risk for mortality (OR 1.05; 95\% CI 1.01-1.09, $\mathrm{p}=0.022$ ). Each additional day on the ICU increased the mortality risk by $5 \%$.

Detailed information is given in tables $2-4$.

Variables without Statistically Significant Influence on ICU and/or Day-100 Mortality

\section{Age and Gender}

There was no significant influence of age or gender of the atients on the mortality.

\section{Underlying Hematological Disease}

Acute myeloid leukemia was the most common diagnosis ( $\mathrm{n}=25 ; 27.8 \%$ ), followed by high-grade non-Hodgkin's lym- phoma (NHL; $\mathrm{n}=18 ; 20.0 \%)$ and multiple myeloma $(\mathrm{n}=13$; $14.4 \%)$. Other malignancies included: low-grade NHL ( $\mathrm{n}=8$; $8.9 \%$ ), acute lymphatic leukemia (AML; $\mathrm{n}=7 ; 7.8 \%$ ), Hodgkin's lymphoma $(\mathrm{n}=6 ; 6.7 \%)$, myelodysplastic syndrome $(\mathrm{MDS} ; \mathrm{n}=5 ; 5.5 \%)$, chronic myeloid leukemia $(\mathrm{n}=4 ; 4.4 \%)$, chronic lymphatic leukemia $(\mathrm{n}=2 ; 2.2 \%)$, and non-malignant hematological diseases $(n=2 ; 2.2 \%)$. Comparing the outcome of the leukemias $(n=43,47.8 \%)$ to the lymphomas $(n=45$, $50 \%$ ) yielded no significant difference in terms of mortality.

Analyzing the ICU and day-100 mortality of subgroups compared to patients with AML yielded no statistically significant differences for patients with high-grade lymphomas, multiple myelomas, low-grade lymphomas, and MDS. Nevertheless there was a trend towards a better outcome in patients with low-grade lymphomas, and a trend towards a worse outcome in those with MDS.

\section{Leukocyte Count}

Mortality was not significantly influenced by leukopenia of any extent.

\section{Mechanical Ventilation}

Patients needing mechanical ventilation had a significantly higher ICU and day-100 mortality by univariate analysis ( $p<0.0001$ and $p=0.0059$, respectively), but the variable failed to show significant influence on the mortality in the multivariate regression analysis.

Detailed information is given in tables 2-4.

\section{Discussion}

Generally, cancer patients are at high risk to be refused by the ICU. With good reason, oncologists and intensivists reserve ICU admission for select cancer patients with potentially reversible medical conditions and a reasonable prospect of substantial recovery [12]. Moreover, there is growing evidence that the mortality of patients with HM during or after their stay on the ICU does not depend on factors associated with the malignancy [13]. Maschmeyer and co-authors reported on a retrospective outcome analysis of 189 consecutive cancer patients referred to the ICU as emergencies during a 2-year period. They identified sepsis, mechanical ventilation, vasopressor support, renal replacement therapy, and neutropenia as independent risk factors for fatal outcome. But restrictively, no single factor unequivocally predicted death [13]. 
Table 4. Variables analyzed for influence on day-100 mortality

\begin{tabular}{|c|c|c|c|c|}
\hline \multirow[b]{2}{*}{ Day-100 mortality } & \multirow{2}{*}{$\begin{array}{l}\text { Univariate log-rank test } \\
\mathrm{p} \text { Value }\end{array}$} & \multicolumn{3}{|c|}{ Multivariate COX regression } \\
\hline & & $\mathrm{HR}$ & CI $(95 \%)$ & $\mathrm{p}$ Value \\
\hline \multicolumn{5}{|l|}{ ICU admission diagnosis } \\
\hline Sepsis & \multirow{4}{*}{0.0102} & 1.91 & $0.65-5.59$ & 0.238 \\
\hline Respiratory failure & & 2.50 & $1.01-6.23$ & 0.048 \\
\hline Others & & 2.58 & $0.82-8.13$ & 0.106 \\
\hline PI care & & Ref. & & \\
\hline \multicolumn{5}{|l|}{ Gender } \\
\hline Male & \multirow{2}{*}{0.4027} & - & & \\
\hline Female & & - & & \\
\hline \multicolumn{5}{|l|}{ Age } \\
\hline$\geq 50$ years & \multirow{2}{*}{0.9137} & - & & \\
\hline$<50$ years & & - & & \\
\hline \multicolumn{5}{|l|}{ Leukopenia } \\
\hline$<0.1 \mathrm{G} / 1$ & \multirow{3}{*}{0.7504} & - & & \\
\hline$\geq 0.1 \mathrm{G} / 1$ & & - & & \\
\hline No leukopenia & & - & & \\
\hline \multicolumn{5}{|l|}{ Norepinephrine $^{\mathrm{a}}$} \\
\hline$\geq 3 \mathrm{mg} / \mathrm{h}$ & \multirow{2}{*}{$<0.0001$} & 2.96 & \multirow[t]{2}{*}{$1.61-5.42$} & \multirow[t]{2}{*}{$<0.0001$} \\
\hline$<3 \mathrm{mg} / \mathrm{h}$ & & Ref. & & \\
\hline \multicolumn{5}{|l|}{ Renal replacement } \\
\hline CVVH/HD & \multirow{2}{*}{0.0174} & 1.93 & \multirow[t]{2}{*}{$1.08-3.46$} & \multirow[t]{2}{*}{0.026} \\
\hline No renal replacement & & - & & \\
\hline \multicolumn{5}{|l|}{ SAPS II } \\
\hline$\geq 54$ & \multirow{2}{*}{0.0027} & - & & \\
\hline$<54$ & & - & & \\
\hline SAPS II & - & 1.02 & $1.00-1.04$ & 0.027 \\
\hline \multicolumn{5}{|l|}{ Mechanical ventilation } \\
\hline Yes & \multirow{2}{*}{0.0059} & 0.91 & \multirow[t]{2}{*}{$0.45-1.87$} & \multirow[t]{2}{*}{0.811} \\
\hline No & & Ref. & & \\
\hline \multicolumn{5}{|l|}{ Underlying malignancy } \\
\hline Leukemia & \multirow{3}{*}{0.3495} & - & & \\
\hline Lymphoma & & - & & \\
\hline Others & & - & & \\
\hline
\end{tabular}

$\mathrm{HR}=$ Hazard ratio; Ref. = reference CVVH = continuous veno-venous hemofiltration; $\mathrm{HD}=$ hemodialyis PI care = post-interventional care (surgery, invasive procedures).

The second column shows p values of the respective univariate Chi-squared tests. A multivariate logistic regression was performed with significant variables of the univariate tests.

${ }^{\mathrm{a}}$ Norepinephrine $3 \mathrm{mg} / \mathrm{h}=50 \mu \mathrm{g} / \mathrm{min}$ (averaged $70 \mathrm{~kg}=0.71 \mu \mathrm{g} / \mathrm{kg} / \mathrm{min}$ ).

Comparable to patients without malignant disease, respiratory failure (41-45\%) and sepsis (24-33\%) were major reasons for ICU admission in this patients group. Their outcome was adversely influenced by high points in different scores assessing organ failure, hemodynamic instability, and mechanical ventilation as parameters for the severity of the disease that finally leads to ICU admission. Similarly to patients without cancer, mortality ranked between 30 and $69 \%$ in these patients [1-8].

These findings need to be pointed out as the fatality of malignant diseases perceived by physicians still exceeds the expected mortality [14]. To contribute to the discussion concerning ICU admission of HM patients, we retrospectively analyzed data from 90 patients admitted to the medical ICU of the university hospital in Munich, Germany, over 13 months.

Certainly, the present data are affected by several factors: The study represents data from a single center, and these data were collected retrospectively. Moreover, the study reflects the decision of a single center for or against ICU admission, bearing the potential risk of a pre-ICU selection bias. We did not analyze patients with very advanced malignancies who were not referred to the ICU. Finally, statements regarding differences in the outcome of subgroups are restricted by low patient numbers.

In accordance with the findings of Maschmeyer et al. [13], with multivariate regression analysis, we found the ICU and/or day-100 mortality to be significantly associated with the reason for ICU admission, like sepsis and acute respiratory failure, and with parameters for acute illness, namely a high SAPS II, high doses of catecholamines, renal replacement therapy, and length of ICU stay. Patients admitted for post-interventional care had a significantly better survival than patients admitted for acute medical illness, probably due to a selection bias before surgical intervention and a prophylactic ICU admission in some cases of post-interventional observation. Additionally, the duration of the ICU stay was a predictor for higher mortality with an increase in mortality of $5 \%$ per day, although some patients deceased within a few days on the ICU with severe gram-negative sepsis, pointing out the importance of this variable. As others have shown before, leukopenia and type of HM did not generally influence the patient outcome [1-5]. Even in the study of Maschmeyer et al. [13], neutropenia as a single risk factor unequivocally predicted death. 
The division into groups like 'leukemia' and 'lymphoma' is rather rough and may not serve well to clarify whether the type of HM influences mortality. Clearly, we found different mortality rates within subgroups, with a trend towards a better outcome of patients with low-grade lymphomas and a worse outcome of those with MDS. But the interpretation of these findings is hampered by the remaining low patient numbers within these subgroups. A division into more precisely defined disease groups, along with analyses of other variables concerning the HM, e.g. disease stage or previous chemotherapy, should be made with larger patient groups to address this question. Despite the broad age range of the patients in the existing patient group (mean 56 years, range $21-85$ years), age did not significantly influence the outcome. This was contrarily observed in other studies, which have shown an association of older age and mortality [9]. Although mechanical ventilation is an indicator for severe respiratory failure and a procedure constituting a risk factor on its own, the necessity of mechanical ventilation significantly influenced the outcome only in the univariate analysis. This is probably due to the small patient group analyzed for its interconnection with the variable 'acute respiratory failure', a patient group with high mortality, as well as with the variable 'post-interventional observation' with low mortality. Indeed, another study confirmed that ICU mortality was lower in post-surgical cancer patients, even when they required mechanical ventilation [15].

Far from questioning ICU admission of patients with HM, Hampshire et al. [6] found the hospital mortality of HM patients to be associated with a long hospital stay before ICU admission and severe sepsis; this suggests considering an early
ICU admission of these patients. Fu et al., however, analyzed the survival of patients with metastatic cancer (MC) requiring ICU admission and observed disastrous survival times for patients needing medical ICU care (2.5 weeks), mechanical ventilation (6 days) and cardio-pulmonary resuscitation (CPR; 1 day). Contrarily, they observed better survival times in patients requiring ICU observation after post-surgical intervention alone (21.5 weeks), probably due to a selection bias before surgical intervention and a prophylactic admission diagnosis to the ICU in some cases. On the other hand, it was noted that patients who required ICU admission for postsurgery/interventional care, and even a small portion of patients who were admitted to the ICU for nonsurgical reasons, survived for more than 1 year [14].

Similarly to these findings, the present study showed that not only the severity of the acute illness but also the reason for ICU admission determined the survival of patients with HM. Although the underlying malignancy loses some importance in this setting, optimism concerning the survival of these patients after ICU admission seems to be out of place. It may be reasonable to consider ICU admission in cancer patients independently of the underlying malignancy for post-interventional care and to discuss admission for other reasons on an individual basis with the patients and their families.

\section{Disclosure Statement}

The authors declare no conflict of interest.

\section{References}

1 Ferra C, Marcos P, Misis M, Morgades M, Bordeje ML, Oriol A, Lloveras N, Sancho JM Xicoy B, Batlle M, Klamburg J, Feliu E, Ribera JM: Outcome and prognostic factors in patients with hematologic malignancies admitted to the intensive care unit: A single-center experience. Int J Hematol 2007;85:195-202.

2 Cherif H, Martling CR, Hansen J, Kalin M, Bjorkholm M: Predictors of short and long-term outcome in patients with hematological disorders admitted to the intensive care unit for a life-threatening complication. Support Care Cancer 2007;15: 1393-1398.

3 Regazzoni CJ, Irrazabal C, Luna CM, Poderoso JJ: Cancer patients with septic shock: Mortality predictors and neutropenia. Support Care Cancer 2004;12:833-839.

4 McGrath S, Chatterjee F, Whiteley C, Ostermann M: ICU and 6-month outcome of oncology patients in the intensive care unit. QJM 2010;103:397-403.

5 Soares M, Salluh JI, Torres VB, Leal JV, Spector N: Short- and long-term outcomes of critically ill patients with cancer and prolonged ICU length of stay. Chest 2008;134:520-526.

6 Hampshire PA, Welch CA, McCrossan LA, Francis K, Harrison DA: Admission factors associated with hospital mortality in patients with haematological malignancy admitted to UK adult, general critical care units: A secondary analysis of the ICNARC case mix programme database. Crit Care 2009;13:R137.

7 Vandijck DM, Benoit DD, Depuydt PO, Offner FC, Blot SI, Van Tilborgh AK, Nollet J, Steel E, Noens LA, Decruyenaere JM: Impact of recent intravenous chemotherapy on outcome in severe sepsis and septic shock patients with hematological malignancies. Intensive Care Med 2008; 34:847-855.

8 Souza-Dantas VC, Salluh JI, Soares M: Impact of neutropenia on the outcomes of critically ill patients with cancer: A matched case-control study. Ann Oncol 2011;22:2094-2100.

9 Maccariello E, Valente C, Nogueira L, Bonomo H Jr, Ismael M, Machado JE, Baldotto F, Godinho M, Rocha E, Soares M: Outcomes of cancer and non-cancer patients with acute kidney injury and need of renal replacement therapy admitted to general intensive care units. Nephrol Dial Transplant 2011;26:537-543.

10 Thiery G, Azoulay E, Darmon M, Ciroldi M, De Miranda S, Levy V, Fieux F, Moreau D, Le Gall JR, Schlemmer B: Outcome of cancer patients considered for intensive care unit admission: A hospital-wide prospective study. J Clin Oncol 2005;23:4406-4413.
11 Le Gall JR, Lemeshow S, Saulnier F: A new simplified acute physiology score (SAPS II) based on a European/North American multicenter study. JAMA 1993;270:2957-2963.

12 Guidelines for intensive care unit admission, discharge, and triage. Task force of the American College of Critical Care Medicine, Society of Critical Care Medicine. Crit Care Med 1999;27:633-638

13 Maschmeyer G, Bertschat FL, Moesta KT, Hausler E, Held TK, Nolte M, Osterziel KJ, Papstein V, Peters M, Reich G, Schmutzler M, Sezer O, Stula M, Wauer H, Wortz T, Wischnewsky M, Hohenberger P: Outcome analysis of 189 consecutive cancer patients referred to the intensive care unit as emergencies during a 2-year period. Eur J Cancer 2003;39:783-792.

14 Wachter RM, Luce JM, Hearst N, Lo B: Decisions about resuscitation: Inequities among patients with different diseases but similar prognoses. Ann Intern Med 1989;111:525-532.

15 Fu S, Hong DS, Naing A, Wheler J, Falchook G, Wen S, Howard A, Barber D, Nates J, Price K, Kurzrock R: Outcome analyses after the first admission to an intensive care unit in patients with advanced cancer referred to a phase I clinical trials program. J Clin Oncol 2011;29:3547-3552. 